\title{
Reconocimiento mutuo como trabajo de traducción ${ }^{1}$
}

\author{
Mutual Recognition as a Translation Work
}

Recibido: 29 de noviembre de 2018. Revisado: 24 de enero de 2019. Aceptado: 31 de enero de 2019.

\section{Manuel Prada Londoño ${ }^{2}$}

\section{Resumen}

El reconocimiento mutuo puede ser pensado como un trabajo de traducción. El punto de partida es la figura del moverse entre mundos» que usan Boltanski y Thévenot para referirse a la capacidad de los sujetos de habitar distintas «escalas de grandeza», y que Ricœur compara con la capacidad de traducir. Nos fijamos en cinco aspectos de la traducción relacionados con el reconocimiento mutuo: (a) su doble sentido: traducción entre lenguas y traducción como interpretación; (b) la relación entre fidelidad y traición; (c) el proceso de formación que experimenta quien traduce; (d) la transformación de la lengua misma del traductor; y, (e) la articulación entre universalidad del lenguaje y pluralidad de las lenguas evidente en el trabajo de traducción.

\section{Palabras clave}

Reconocimiento mutuo, escalas de grandeza, trabajo de traducción, Paul Ricœur.

\begin{abstract}
The paper exposed that mutual recognition could be approached as a translation work. The starting point is the "moving between worlds", used by Boltanski and Thévenot to refer to the subjects' capacity to live in different "orders of worth", which Ricœur compared with the ability to translate. We examined five aspects of translation related to mutual recognition: a) its double meaning: translation between languages and translation as interpretation; b) the relationship between fidelity and betrayal; c) the training process experienced by the translator; d) the transformation of the translator's own language; and, e) the articulation between the universality of the language and the plurality of the languages evident in the translation work.
\end{abstract}

\section{Keywords}

Mutual recognition, orders of worth, translation work, Paul Ricœur.

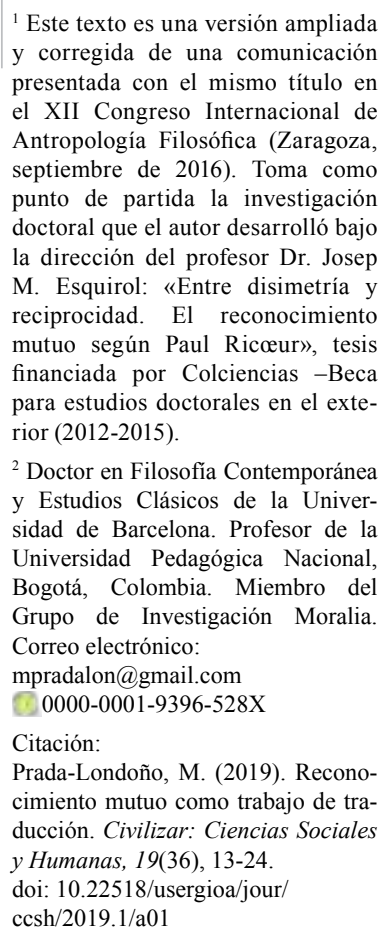

${ }^{1}$ Este texto es una versión ampliada y corregida de una comunicación presentada con el mismo título en el XII Congreso Internacional de Antropología Filosófica (Zaragoza, septiembre de 2016). Toma como punto de partida la investigación doctoral que el autor desarrolló bajo la dirección del profesor Dr. Josep M. Esquirol: «Entre disimetría y reciprocidad. El reconocimiento mutuo según Paul Ricœur», tesis financiada por Colciencias -Beca para estudios doctorales en el exterior (2012-2015).

${ }^{2}$ Doctor en Filosofía Contemporánea y Estudios Clásicos de la Universidad de Barcelona. Profesor de la Universidad Pedagógica Nacional, Bogotá, Colombia. Miembro del Grupo de Investigación Moralia. Correo electrónico: mpradalon@gmail.com 0000-0001-9396-528X

Citación:

Prada-Londoño, M. (2019). Reconocimiento mutuo como trabajo de traducción. Civilizar: Ciencias Sociales y Humanas, 19(36), 13-24. doi: 10.22518/usergioa/jour/ $\operatorname{ccsh} / 2019.1 / \mathrm{a} 01$ 


\section{Introducción}

La traducción se ha ido convirtiendo en un tema central de la filosofía contemporánea, ligado al llamado giro lingüístico ${ }^{1}$. La atención de los trabajos relacionados con este tema se ha puesto no solo en problemas que podríamos llamar estrictamente lingüísticos -lógicos o filológicos, por ejemplo- referidos de modo general al ejercicio de pasar un texto de una lengua a otra, sino también en diversos aspectos de nuestra condición humana que se ponen de relieve cuando traducimos ${ }^{2}$. Así, nuestro modo particular de habitar lingüísticamente el mundo, la forma como tejemos lazos sociales, la comprensión de nuestra pluralidad y la posibilidad de establecer vínculos entre culturas, tradiciones, maneras de entender la vida, o incluso la capacidad humana de hospitalidad son solo algunos asuntos derivados de una filosofía de la traducción.

Paul Ricœur toma parte de este movimiento del pensar, encarnado en su propia experiencia como traductor y políglota: como traductor, descuella su versión de Ideen I de Husserl, proyecto iniciado en su cautiverio en Pomerania, durante la Segunda Guerra Mundial; como políglota, recuérdese la facilidad con que transitaba por el francés, el inglés, el alemán, el griego y el latín, sin olvidar el castellano y el italiano. Además de este motivo biográfico, Ricœur puso en valor el problema de la traducción en especial durante el último periodo de su periplo intelectual para pensar problemas como la hospitalidad, el reconocimiento o el don.

En lo que concierne a su filosofía del reconocimiento mutuo, en particular, desarrollada en Parcours de la reconnaissance, la traducción constituye uno de los ejemplos de la posibilidad del reconocimiento no solo por vía de la «lucha», sino como estado de paz. En otras palabras: cuando traducimos, de cierto que una lengua choca con otra, quiere ser reconocida en la especificidad de sus matices, en las diferencias semánticas que permite o en su plasticidad; la lengua a la que se traduce también quiere dar cuenta de su propia capacidad de adaptación y, por qué no decirlo, de su versatilidad para que lo expresado en la otra lengua gane un color renovado -lo que, ciertamente, puede acontecer en el trabajo de traducción-. Pero en ella no solo hay lucha, sino que también nos es dado comprender un vínculo entre los seres humanos. Así, en palabras de D. Jervolino, uno de los estudiosos de Ricœur que más ha desarrollado una filosofía de la traducción inspirada en el autor de Soi-même comme un autre:

El don de la lengua y de las lenguas [don que, añadamos, se experimenta en el trabajo de traducción, en el mutuo darse de una lengua a otra] se convierte en paradigma de un elemento de gratuidad que corrige la obsesión contemporánea por la mercantilización generalizada de los mundos vitales y deja entrever un posible fundamento del vínculo social en perspectiva de solidaridad y solicitud por las personas en su concreción. (Jervolino, 2008, p. 135).

Del mismo modo, la traducción vista como ejercicio de hospitalidad da pie para afirmar que el vínculo social está cimentado no solo en la lucha, sino en vías no-violentas que, además, permiten "cultivar una esperanza de sentido para el convivir humano", así como "contrastar, para usar un lenguaje que evoca reminiscencias kantianas, el mal radical que es la violencia operante en la historia, y reivindicar contra ella la dignidad moral originaria del ser humano en cuanto tal, la humanidad de los humanos en cuanto vivientes provistos de logos" (Jervolino, 2008, p. 134).

Sin perder de vista esta interpretación, en el presente texto seguiremos de cerca el pasaje del tercer estudio de Parcours de la reconnaissance en el que Ricœur se centra en la estima social, especialmente a la luz de la obra de los sociólogos Luc Boltanski y Laurent Thévenot titulada De la justification ${ }^{3}$. El presente artículo, que pretende continuar la reflexión de Jervolino en torno a múltiples implicaciones de 
la traducción, defiende la tesis según la cual la capacidad de «moverse entre escalas de grandeza», cuyo alcance puede ampliarse a la capacidad de moverse entre la diversidad de proyectos de vida, reivindicaciones de justicia, luchas sociales, puede leerse a la luz de la idea de un trabajo de traducción.

\section{Reconocimiento mutuo y escalas de grandeza}

Con Hegel y Honneth como compañeros de trayecto, Paul Ricœur señala que el reconocimiento mutuo se realiza en tres instancias diferentes: las relaciones amorosas, el ámbito del derecho y la estima social (Ricœur, 2004, pp. 294-315; Prada, 2015). Esta última, que usaremos como pretexto para emprender nuestra reflexión, se refiere a la valoración social de las cualidades y diferencias personales de cada quien (Honneth, 1997), y requiere dos movimientos complementarios: uno concerniente al sujeto, que ha aprendido en el transcurso de su vida a aprobarse a sí mismo, sentirse valioso para la sociedad y referir a sí todos los logros por los cuales su vida es valorada como realizada (Honneth, 1997); otro relativo a la evaluación que hace la sociedad de las diversas dimensiones que constituyen una vida en tanto realizada: profesional, laboral, económica, política, estética, etc., que no es posible sino gracias a la existencia de un horizonte de valores intersubjetivamente compartido.

Tal horizonte es resultado de un proceso de sedimentación en el que confluyen muchas fuentes de sentido, introducidas por sujetos plurales, históricamente situados; las aspiraciones de estos sujetos injertan proyectos inéditos de vida realizada en las aspiraciones ya existentes, que comienzan a ser considerados plausibles y abren objetivos éticos que ingresan al acervo de valoración social (Honneth, 1997). A su vez, el sujeto se ve abocado a responder por la deuda contraída tanto con aquellos que en su día abrieron nuevos horizontes de sentido, como con los que están por nacer o recién llegan al mundo y esperan ser recibidos en una sociedad que no ha roto los vasos comunicantes entre tradición y crítica.

La estima social requiere que los sujetos sean considerados por sus propias capacidades individuales, cuya pluralidad enriquece la vida social. A esta forma de valoración se le conoce como prestigio, que "nombra el grado de reconocimiento social que merece el singular por la forma de autorrealización, porque con ella contribuye en una determinada medida a la conversión práctica de los objetivos abstractamente definidos de la sociedad" (Honneth, 1997, p. 155). No se pierda de vista que en el prestigio se ve cómo opera la relación individuo-sociedad a la que nos acabamos de referir: por un lado, en la sociedad ya están definidas pautas de valoración, prácticas sociales e instituciones que deberían servir como caldo de cultivo para que cada quien alcance la estima que puede y a la que aspira; por otro, el sujeto asume y aprovecha dichas pautas, a la vez que las transforma, al enriquecerlas, criticarlas o abandonarlas, con la novedad que le es propia a su capacidad de acción.

Ahora bien, debe tenerse presente que al hablar de valoración social, nos referimos no solo a conflictos que acaecen entre identidades culturales o de otra índole que pugnan por ser reconocidos $^{4}$; también ha de considerarse que un mismo sujeto en una misma sociedad es estimado en diferentes contextos, según criterios diversos que, incluso, pueden llegar a entrar en contradicción, y que no están vinculados -al menos no directamente- a problemas propios de lo que suele llamarse identidad cultural. Para abordar este asunto particular del reconocimiento mutuo, en Parcours de la reconnaissance Ricœur se remite al trabajo de Luc Boltanski y Laurent Thévenot titulado De la justification. Les économies de la grandeur ${ }^{5}$.

Si con la lectura de Honneth, Ricœur hallaba la relación individuo-sociedad, con la obra de estos sociólogos franceses el filósofo entiende que la estima social se juega en la ten- 
sión productiva entre una pluralidad de escalas de grandeza y un cierto tipo de universalidad que reclama que todos los seres humanos, sin excepción, importen independientemente de cómo sean estimados. Del lado de la pluralidad está la diversidad de "empresas gramaticales de explicitación y fijación de reglas de acuerdo", "modelos de la competencia común exigida a las personas para que este acuerdo sea posible" (Boltanski y Thévenot, 1991, p. 86), que tienen la forma de una ciudad bien ordenada que satisface principios superiores de bien común y sirven de criterio de justicia capaz de orientar la acción. Así, tenemos la ciudad inspirada, cuyos principios de éxito son la gracia y el amor silenciosos, que no pretenden aparecer ante otros; la ciudad doméstica, basada en la posición jerárquica, el rango y el linaje, que privilegia el modelo patriarcal doméstico; la de la opinión, que tiene en el buen nombre y el crédito y honor atribuidos por otros su criterio de grandeza; la ciudad cívica, que exalta la subordinación a la voluntad general mediante el contrato social, "que hace que todo ciudadano contratase consigo mismo y no opinase más que según él mismo, al contrario del contrato de sumisión del Leviatán" (Ricœur, 2004a, p. 303); la ciudad mercantil (Boltanski y Thévenot, 1991, pp. 60-82), regida por la identificación de bienes raros o escasos, que interesan a todos, y por la regulación de los intercambios comerciales; por último, la ciudad industrial, cuyo criterio de bien común es la satisfacción de necesidades (Boltanski y Thévenot, 1991, pp. 107-157).

Boltanski y Thévenot vinculan una revisión de diversos manuales destinados a empresas o sindicatos, cuyo propósito es orientar concretamente la acción de los sujetos, a las grandes obras de la filosofía política. A partir de la revisión de estos manuales, establecen una asociación entre los principios de las ciudades y determinados objetos que sirven como apoyo de las personas y como recurso simbólico para señalar la grandeza de una persona en determinada situación; asimismo, muestran cómo a cada ciudad corresponden determinadas prue- bas que permiten establecer el tipo de grandeza o restaurar una grandeza pretendida en determinado momento. La articulación entre principios de grandeza, objetos y pruebas configura lo que los autores denominan mundos.

Del lado de la universalidad, se señalan varios principios que sostienen el modelo de las economías de grandeza: (a) todos los miembros de la ciudad ostentan, sin excepción, un título común de humanidad (Boltanski y Thévenot, 1991) y una capacidad de elevarse por encima de las circunstancias particulares para buscar el bien común (p. 178); asimismo, (b) no existe un modelo único de Ser Humano, al modo de un Adán perpetuo, sino seres humanos diferentes, singulares, cuya posición (o estado) en la ciudad puede variar, y que se valen de $o b$ jetos diferentes (p. 179) que fungen como referentes de los logros alcanzados en el interior de cada ciudad; del mismo modo, (c) todos los seres humanos tienen un poder idéntico de acceso a todos los estados posibles dentro de una ciudad, estados que están bien ordenados según una (d) escala de valores, necesaria para coordinar las acciones y justificar las distribuciones de bienes. Como existe una tensión entre el primer axioma (común humanidad) y este último, que hace evidente que hay diferencias entre los seres humanos en virtud de sus logros (que los autores denominan «grandezas»); en otras palabras, como no todos están en el nivel supremo (al modo de un Edén), se requiere introducir la siguiente hipótesis: existe una fórmula de inversión que liga los bienes de los estados superiores con una cuota de sacrificio necesaria con la que se accede a ellos. Para que esta hipótesis no legitime una sociedad injusta, Boltanski y Thévenot acuden a dos axiomas suplementarios: (e) los bienes que se disfrutan en los estados superiores benefician a toda la ciudad; en suma, "es el beneficio de la ciudad lo que constituye el principio superior de todos los bienes obtenibles" (pp. 96-103); y (f) hay que mantener una "obligación destinada a prohibir que se asocie de forma definitiva a las personas con un determinado estado de grandeza, tratándolo como si fuera consustancial" (Boltanski, 2014, 
p. 53). Estos últimos criterios tienen que ser complementados con un criterio superior, no tanto desde el punto de vista del análisis sociológico como de su base ética y antropológica: (g) los seres humanos importan independientemente de cuál sea su grandeza (Boltanski y Thévenot, 1991, p. 169).

En suma, lo que le interesa a Ricour en su lectura de esta obra de la sociología no es tanto el conjunto de detalles que se exponen sobre lo específico de cada ciudad o mundo, ni problematizar las fuentes consultadas o cuestionar los ejemplos usados por estos autores. Más bien el filósofo se concentra en la declaración según la cual lo que reconocemos en otros y pedimos que nos sea reconocido es, en últimas, nuestra condición de seres humanos dignos de estima y respeto; pero como tal condición es siempre plural, también nos jugamos la vida en el reconocimiento recíproco de la validez de diversas formas de vida, así como de las distintas aristas que configuran nuestra existencia individual y colectiva.

Que la condición humana sea plural se manifiesta, entre muchas circunstancias, en que las personas en su día a día afrontan diferentes situaciones de diversos mundos y saben reconocerlas y ajustarse a ellas (Boltanski y Thévenot, 1991, p. 266). De la justification dedica varias páginas a mostrar cómo puede haber relaciones entre mundos y a describir cuáles son las condiciones de validez de las pruebas resultantes; no conforme con la descripción, ese trabajo muestra la función crítica de dichas relaciones: por un lado, cuantos más mundos conozcan las personas, más posibilidades tienen de:

Cuestionar la validez de las pruebas a las cuales son sometidos, sin limitarse a cuestionar la distribución de las grandezas. El conocimiento de estos mundos permite cuestionar la validez de la prueba mostrando que ella está afectada por la presencia de cosas de otra naturaleza o porque los objetos del mundo de los que ella emerge son defectuosos. (p. 270).
Por otro, la función crítica también radica en que a veces una misma situación puede y debe ser juzgada a la luz de dos pruebas distintas, y cada una de tales pruebas habrá de dar cuenta de un aspecto constitutivo y configurar entre ambas una distribución más equitativa de los bienes en juego.

A esta altura de la exposición, los sociólogos franceses, y Ricœur con ellos, dejan claro que los mundos plurales que configuran la vida social no establecen una relación de indiferencia -como si el ciudadano de un mundo o las pruebas que le son propias no pudieran ni quisieran dejarse instruir o criticar de ciudadanos, pruebas y objetos de otra ciudad-o de incompatibilidad absoluta -lo cual implicaría afirmar que una persona solo puede ser habitante de una ciudad-. Más bien una pluralidad tal invita a vivir el arte de comportarse en determinadas situaciones, según las circunstancias, los objetos y las personas particulares; a establecer relaciones entre mundos y objetos, y sobre todo a comprometerse con el bien común que no pierde de vista el «axioma» básico que hemos ya enunciado: toda vida, todo ser humano importa ${ }^{6}$.

La pluralidad de la condición humana manifiesta en la pluralidad de mundos invita también a pensar la formación de los sujetos como capacidad de vivir en sociedad aprendiendo a moverse entre ciudades, a enriquecer el proyecto personal de vida con una diversidad cada vez más rica de puntos de vista y a aceptar las divergencias entre criterios de realización personal. Todo ello no es posible si los sujetos no pueden sumergirse (Boltanski y Thévenot, 1991, p. 172) en una ciudad distinta, "donarse" (p. 182) a cada situación, "ponerse a su disposición" (p. 184) elevándose por encima de sus circunstancias.

\section{La capacidad de traducir}

Sumergirse, donarse, ponerse en disposición, moverse entre mundos, establecer relaciones creativas entre ellos para criticar lo ya 
existente y buscar el bien común: todas estas son figuras comparadas por Ricœur con la capacidad de:

Aprender una lengua extranjera hasta el punto de percibir su propia lengua como una entre las demás. Si la traducción misma puede interpretarse como un modo de hacer comparable los incomparables... es la capacidad para el compromiso la que abre la puerta privilegiada al bien común. (2004a, pp. 305-306).

Así las cosas, ¿en qué sentido reconocer a otros según escalas de grandeza diferenciadas requiere ejercer la capacidad de traducción? De modo más general, ¿por qué el reconocimiento mutuo puede ser asumido como un trabajo de traducción?

La respuesta a estas preguntas comienza a plantearse a la luz de dos sentidos diferentes de la traducción: uno limitado, que la asume como «transferencia de un mensaje verbal de una lengua a otra»; y otro más amplio, que la considera como sinónimo de interpretación (Ricour, 2004b; Steiner, 2001). En la propuesta de Boltanski y Thévenot, cada una de las ciudades conforma una gramática en la que podemos identificar sujetos de predicación, juicios, formas de enunciación, símbolos, gestos, etc. Moverse entre ciudades es moverse entre gramáticas particulares, que es lo que hace justamente un traductor; las disputas entre ciudades que reclaman de los sujetos esfuerzos tendientes a establecer compromisos pueden ser análogas a las disputas que acaecen entre hablantes de dos lenguas distintas sobre la justeza de una expresión o sobre los matices de un giro cuyo sentido se resiste a dejarse ver en la otra lengua; o entre hablantes de una misma lengua que, sin embargo, no se entienden y se ven forzados a responder o preguntar: «¿qué quiso usted decir con esto (gesto, símbolo, prueba, objeto)?». «Decir de múltiples maneras» la grandeza de una persona es el reto que afronta una sociedad que pretende ampliar los marcos de referencia del reconocimiento mutuo.
Un segundo aspecto que se puede resaltar aquí concierne al intento de Ricœur por sobrepasar la disputa entre dos formas improductivas de abordar el problema de la traducción: o no es posible en absoluto traducir porque cada lengua es inconmensurable, cerrada, o se puede traducir de modo perfecto porque todas las lenguas tienen una estructura profunda homogénea, un fondo común o lengua originaria (Ricœur, 2004b). La práctica de la traducción, de muy vieja data entre viajeros, comerciantes o diplomáticos, así como el testimonio de los que habitan en dos o más lenguas, niegan la imposibilidad radical de la traducción. Por otro lado, y como lo ha mostrado profusamente la investigación contemporánea, no existe una lengua universal, una gramática homogénea subyacente a todas las lenguas, ni la posibilidad de verificar que existe una traducción perfecta, dado que sería necesario acudir a un texto que no solo permita comparar la traducción con el original, sino a establecer criterios contundentes para dar un veredicto ${ }^{7}$. En ausencia de un texto semejante, lo que queda es emprender una traducción nueva que corrige a la anterior y que queda abierta a correcciones ulteriores.

Sobre la estima social en particular, y el reconocimiento mutuo en general, podría decirse algo análogo: es necesario escapar a una alternativa que plantea o la heterogeneidad absoluta entre los seres humanos, o entre formas de vida, proyectos, justificaciones y bienes; o una «igualdad» a priori que aplana o niega las diferencias entre los seres humanos. Si nos atenemos al modelo de grandezas propuesto por Boltanski y Thévenot, veremos que la mera descripción de la vida humana en las sociedades en las que vivimos da cuenta de la futilidad de la idea de una heterogeneidad insuperable, pues cualquiera de nosotros puede vivir -y de hecho vive, como se dijo atrás- en dos o más ciudades y hace tránsitos entre ciudades de forma cotidiana. Asimismo, es difícil sostener una comprensión adecuada de la vida social ligada a la idea de una igualdad de capacidades y grandezas entendida con la pretensión de que 
«todos sean y valgan lo mismo»: iguales como artistas, o poseedores del mismo dinero, o de las mismas habilidades para el arte, o de la misma capacidad de liderazgo, etc.; así también resulta problemática la declaración de una «igualdad» humana ciega a las diferencias de cualquier otra índole.

Ahora bien, la renuncia a esta opción no atañe solo a su escaso valor descriptivo, sino que también se ampara en una demanda de carácter ético y político: por una parte, la declaración de una heterogeneidad absoluta entre los seres humanos es el caldo de cultivo de la indiferencia ante los otros, la exclusión de los que no pertenecen a mi ciudad o la mera incomunicabilidad que habrá que aceptar con resignación; del mismo modo, puede ser el obstáculo para configurar proyectos comunes capaces de aunar reivindicaciones particulares con exigencias globales de justicia. Por otro lado, la insistencia en una igualdad homologadora niega la particularidad de cada uno de los seres humanos, desconoce, por ejemplo, las destrezas diferenciadas entre las personas, así como la diversidad de proyectos de vida colectivos o de luchas que reclaman ser reconocidas como válidas.

Hemos de aprender el carácter finito de nuestra existencia a partir de la renuncia a una traducción perfecta, que es precisamente a lo que nos enfrentamos radicalmente cuando se nos resisten las palabras, cuando nos hallamos ante la imposibilidad de decirlo todo, y que volvemos a experimentar cuando nos vemos llevados a escuchar las razones del otro, a asumir sus reclamos, a cuestionar los nuestros y a abrazar perspectivas diferentes en aras del bien común. También experimentamos tal finitud cuando nos hallamos frente a la imposibilidad de un «texto superior», de una voz autorizada o juez universal capaz de dirimir los conflictos entre diversas nociones de grandeza.

A la alternativa entre imposibilidad de la traducción justificada en la heterogeneidad absoluta de las lenguas o traducción perfecta, Ricœur contrapone una alternativa más productiva: «fidelidad $o$ traición» (2004b, p. 26). ¿Fidelidad a qué? Ciertamente, al sentido de lo dicho, al sentido del texto; huelga decir que tal fidelidad no presupone una equivalencia de sentidos entre las lenguas ni la eliminación de la especificidad de cada una de ellas; más bien esta fidelidad al sentido se refiere a la capacidad del lenguaje de preservar el secreto del otro -de eso otro que es la otra lengua, la otra cultura- $a$ pesar de todos los inconvenientes que enfrentan los traductores, de los cuales la filosofía y la literatura dan un testimonio fidedigno.

Empero, la tarea de traducir siendo fieles al sentido de un texto está conectada con una tarea mayor: la de guardar fidelidad a un llamado originario a vivir la unidad plural de lo humano que pone de presente el famoso mito de Babel (Ricœur, 2004b, pp. 34-36). Con la lectura del relato del Génesis uno parece convencerse de que, a fin de cuentas, la gran empresa no era la construcción de una torre que tocara el cielo, sino la de tejer los lazos de fraternidad que habían dejado de ser un «hecho» para convertirse en una tarea después del primer fratricidio.

¿Cómo es posible articular la fidelidad a esta unidad con la fidelidad a la pluralidad de lo humano? Para Ricœur, la traducción permite la confluencia entre la universalidad del lenguaje y la pluralidad de las lenguas. Para entender la articulación análoga en el reconocimiento volvamos brevemente al asunto de las grandezas tal como se lee en De la justification. Ya decíamos que Boltanski y Thévenot intentan mostrar que, a pesar de las diferencias entre grandezas, toda vida vale, todo ser humano es digno de estima y respeto, y a ninguno se le puede considerar como ligado definitivamente a una ciudad o grandeza específicas. Sin embargo, Ricœur no deja de advertir que el hecho innegable de que existan diferencias de grandeza entre las personas no solo concierne a la pluralidad, sino que introduce la espina de la verticalidad 
en un proyecto, el del reconocimiento mutuo, caracterizado por su esfuerzo por establecer relaciones horizontales (Ricœur, 2004a, p. 310). Si bien no formula el problema en estos términos, Honneth acude a una de las ideas fuerzas de la eticidad hegeliana para decir que a pesar de las diferencias propias de la estima social, para los seres humanos existe un deber de sentir unos para con otros recíprocos afectos de respeto solidario, instruidos por una orientación a objetivos y valores comunes. Compartimos una humanidad puesta por encima de cualquier pertenencia, adscripción o condición particulares; y tal unión no es solamente una formalidad exigida por la coherencia del sistema filosófico, sino que es una práctica realizada históricamente.

Podemos añadir una consideración más: la articulación entre pluralidad de las lenguas y universalidad del lenguaje ha llevado a autores como Jervolino a ver en la traducción, el paradigma para conciliar la responsabilidad respecto a la propia existencia y a la de los otros «con la verdad de una humanidad que permanece dividida en sí misma»; de la misma forma, este autor retoma las reflexiones emprendidas por Ricœur, especialmente en Soi-même comme un autre, para mostrar que la traducción sirve también como paradigma para pensar "la composiblidad entre las múltiples formas de lo humano" (Jervolino, 2008, p. 194) que se manifiestan en situaciones problemáticas en las que hay incompatibilidad entre lo universal y el contexto, o incluso entre reglas universales. Ricœur se inclina muchas veces a hacer una opción por la excepcionalidad al defender la idea según la cual la prueba a la que se somete lo universal no es otra que la que alumbra la excepcionalidad del rostro, el destinatario último de las promesas a las que las leyes universales sirven ${ }^{8}$. En palabras del profesor italiano, la traducción permite:

Una confrontación-encuentro en el cual la atención y el respeto por la diferencia no hace perder de vista, sin embargo, la prospectiva de un universalismo posible y militante, de un horizonte cosmo-político por conquistar como telos inmanente al dinamismo de la historia hecha, narrada, pensada por los hombres, ciertamente no calmada por algún happy end garantizado previamente, sino donde el dolor de las víctimas y la tragedia de los males sufridos y cometidos puedan encontrar al menos la respuesta de la compasión y de la esperanza, advertida como deuda de quien sobrevive de las confrontaciones de las generaciones pasadas [y de las futuras]. (Jervolino, 2008, pp. 140-141).

Prosigamos. La traducción implica igualmente la fidelidad al otro: tanto a la palabra que llega a mi propia lengua, es decir, "al extranjero en su extranjeridad", como "al lector en su deseo de apropiación" (Ricœur, 2004b, p. 41). El traductor es fiel a su promesa de decir lo que dice el texto, y al mismo tiempo de decirlo de la mejor manera posible en su propia lengua para que lo comprenda todo lector potencial. Y este ejercicio no está exento de luchas y tensiones: el texto en general se me resiste (todo lo que sea otro siempre se resiste); esta resistencia a veces reviste la forma de la superioridad: llego al texto convencido de que mi propia lengua es más bonita o podría decir mejor o más adecuadamente algo; en otras ocasiones toma la forma de la inferioridad y entonces, por ejemplo, me lamento de que mi lengua no tenga la plasticidad de la otra para crear conceptos o una mayor precisión.

Ricœur habla de trabajo de traducción al tomar como guía la idea freudiana de "trabajo de duelo" que ha citado en varios pasajes de su obra (2000, p. 85; 2009, pp. 25-26; 43-49): es «trabajo» precisamente porque es un ejercicio constante, mediado ya no por el analista -como es el caso del psicoanálisis-, sino por la comunidad de lectores, por traducciones en otros idiomas, por el diálogo con otros colegas, por la crítica de los lectores; «duelo» como renuncia a la superioridad de su propia lengua, y también a una traducción perfecta; lucha contra el fantasma de la omnipotencia y esfuerzo 
por recuperarse de la prueba de realidad que siempre está levantando la alteridad del texto. Trabajo de traducción, en suma, que consiste en levantar puentes entre las dos lenguas:

En hacer justicia al espíritu extraño; [traducir] es instaurar la justa distancia entre cuerpos lingüísticos. Tu lengua es tan importante como la mía. Es la fórmula de la equidad-igualdad. $\mathrm{La}$ fórmula de la diversidad reconocida. [...] equivalencia sin identidad que es la fórmula misma de la justicia en el campo de la traducción (Ricœur, 2001, p. 40).

El reconocimiento mutuo puede ser considerado bajo la égida del paradigma de la traducción porque participa del mismo movimiento de fidelidad al otro, aunque (o a pesar de que) ese otro se me resiste, me desacomoda, se mantiene inasible. Muchísimas veces los seres humanos hemos entrado en relación con los otros no con espíritu de fidelidad a su carácter de otro, lo que supone promesa de acogida, solicitud y cuidado, sino más bien con voluntad de dominio, de imposición de nuestras propias formas de ver el mundo, aun amparados en las mejores intenciones (salvación, civilización, derechos humanos, democracia son varios de los nombres que han adoptado estas «buenas» intenciones) (Todorov, 2005). En otras ocasiones, la extrañeza propia de los otros se trueca en miedo, "odio a lo extranjero, percibido como amenaza dirigida contra nuestra propia identidad lingüística" (Ricœur, 2004b, p. 41), lo cual puede ampliarse a cualesquiera formas de identidad individual o grupal. El reconocimiento supone, pues, un trabajo de duelo en la medida en que me exige consentir una de las pérdidas más decisivas de la formación como sujetos capaces de estima de sí y de solicitud: la de la autosuficiencia, que se acompaña de un modo de relación con el otro en el que la «acogida» está condicionada a que éste se asimile a lo que yo soy, hago, pienso o creo (Jervolino, 2008).

Asimismo, la figura del puente nos recuerda una realidad de nuestra condición humana que puede sonar trivial, no obstante lo cual está en el corazón del reconocimiento mutuo y de la justicia debida a cada uno: el puente aproxima, pero no iguala las orillas del río, a pesar de que nuestro diario transitar por él nos haga sentir que no hay distancia. Del mismo modo, la cotidianidad de nuestro vivir juntos a veces oculta las diferencias: compartimos un mismo espacio, nos encontramos en la misma calle, nos comunicamos con los mismos símbolos o participamos en las mismas instituciones. Solo cuando no hay puente en esta parte del camino, o cuando se nos insta a dar una vuelta muy larga para rodear el río, nos damos cuenta de la inconmensurabilidad de las orillas. De forma análoga, podemos decir que el trabajo del reconocimiento mutuo se hace más evidente cuando parece que el puente se ha quebrado, y que, una vez restituido, incluso en el modo más festivo de hospitalidad, seguiremos confesando "la diferencia insuperable entre lo propio y lo extranjero" (Ricœur, 2004b, p. 49). En otras ocasiones, se nos exige que cuestionemos las seguridades de una pretendida igualdad que en realidad esconde las más variadas injusticias en el disfrute de derechos y en la distribución de recursos.

Veamos otro rasgo de la traducción. En su trabajo el traductor no solo aprende más y mejor la lengua extranjera, sino que descubre recursos desconocidos de la suya, nuevas expresiones, o palabras. Ricœur habla de éste como un proceso de formación (Bildung), pues el traductor no solo aprende más de su propio oficio, sino que sobre todo se configura a sí mismo (Ricœur, 2004b, p. 39). Hay una configuración que acaece merced a la lectura que supone toda traducción, al menos si aceptamos la idea de Ricœur según la cual la lectura configura también nuestro quién (Ricœur, 1986; Prada, 2010); en otras palabras, uno de los aportes más significativos a la formación del traductor radica en que su trabajo le permite empinarse para mirar más allá de sí mismo y asumir diversas perspectivas de mundo. Esta asunción, aunada a la de la renuncia a la autosuficiencia, constituye otra de las claves de la formación del sujeto capaz 
de estima, solicitud y responsabilidad: quien traduce logra reconocer que su lengua también es extranjera para otras lenguas, que es una lengua más, que en ella también hay zonas de indecibilidad, imposibilidades y potencias expresivas; que la «propia» lengua quizá no nos es tan propia y que es una seña más de la pasividad en la que se fragua nuestro ser en el mundo: "la prueba ya no es entonces la de lo extraño fuera de nuestras puertas, sino la de la extrañeza en nuestra propia casa; es también necesario acogerse a sí mismo como otro. Inexorable pluralidad, por un lado; impenetrable soledad, por otro" (Ricœur, 2001, p. 37). Y si mi lengua es una lengua entre otras, habré de reconocer que mi «ciudad» lo es, como también lo son mi cultura, mi religión, mis convicciones. Así como intento hablar y escribir del mejor modo en mi lengua; así como aprendo a quererla y a pensar en ella sacando provecho de todos sus recursos, puedo empeñarme en vivir mis convicciones, siempre sometidas a la crítica, pero no perderé de vista su condición insuperable de extranjeridad.

De igual modo, cabe afirmar que no solo la persona del traductor, sino su propia lengua se transforma en la traducción. Sabemos de ello gracias a los célebres ejemplos de la transformación -incluso creación del alemán- gracias a la traducción que hizo Lutero de la Biblia, o del profundo enriquecimiento del castellano gracias al encuentro con obras árabes, judías o americanas. De modo análogo, los criterios esgrimidos por cada una de las ciudades y mundos -para seguir con De la justification- se transforman por su contacto (tensión, discusión, compromiso) con otras ciudades; podemos abrir el panorama de nuestras consideraciones y mencionar el modo como las reivindicaciones de diversos movimientos sociales, al entrar en contacto unas con otras en momentos en los que la situación lo exige, se enriquecen mediante la explicitación de sus propios recursos, así como mediante el cuestionamiento de lo propio implicado en todo diálogo que asume como su condición de posibilidad la renuncia a ser dueños del sentido que exige el tener que volcarse sobre las cosas mismas; procesos análogos de explicitación, ampliación, cuestionamiento y transformación viven las culturas y las religiones que se encuentran en un diálogo auténtico.

\section{Palabras finales}

Al comenzar nuestro recorrido decíamos que la traducción ha sido interpretada como un «paradigma» para entender las preocupaciones filosóficas del último Ricœur. La aproximación que hemos esbozado aquí da cuenta de que, efectivamente, la idea ricœuriana del reconocimiento mutuo -tal como aparece en Parcours de la reconnaissance- puede ser ampliada si se articula con la reflexión sobre la traducción -ligada, a su vez, a un problema mucho más amplio que es de la lingüisticidad de lo humano, aunque de ello no nos hemos ocupado en el presente artículo-.

Ahora bien, quizás sea pertinente indicar que las consideraciones sobre la traducción son aplicables no solo al particular problema de la estima social que ha sido aquí nuestro punto de partida. De hecho, puede sugerirse que la traducción atraviesa todo el itinerario del reconocimiento mutuo. ¿Acaso no se puede hablar de una presencia análoga de la traducción entre formas de considerar las relaciones amorosas, entre principios del derecho y leyes, así como en el entrecruce de las tres instancias del reconocimiento que, a pesar de estar diferenciadas entre ellas, requieren en muchas ocasiones una complementariedad en doble vía que recuerda la dialéctica entre las lenguas?¿No hay acaso problemas sociales y políticos $-v$. gr. un proceso de paz como el que aún se está viviendo en Colombia- que requiere la construcción de vasos comunicantes entre principios de justicia dispares, entre formas de comprender la historia propia y la ajena, lo cual puede pensarse a la luz del trabajo de traducción?

Pensar estos y otros problemas concomitantes no deja de llevarnos a considerar que, en 
todo caso, la traducción es teóricamente difícil, prácticamente fácil (Ricœur, 2004b, p. 27), o al menos practicable. Respecto al reconocimiento mutuo debemos ser cautos y declarar que, muchas más veces de las que quisiéramos, el reconocimiento resulta también prácticamente difícil. La traducción -como el reconocimiento-, dice Ricœur, "se inscribe en larga letanía de los «a pesar de todo». A pesar de los fratricidas [y añadimos con el mismo Ricœur: a pesar de la pluralidad del odio (Ricœur, 2001, p. 34)], militamos por la fraternidad universal. A pesar de la heterogeneidad de los idiomas, hay bilingües, políglotas, intérpretes y traductores" (Ricœur, 2004b, p. 33).

\section{Referencias}

Bielsa, E. (2016). Cosmopolitanism and Translation. Investigations into Experiences of the Foreign. New York, United States: Routledge.

Bolaños, S. (2016). Introducción a la traductología: autores, textos y comentarios. Bogotá, Colombia: Universidad Nacional - Universidad del Rosario.

Boltanski, L. (2014). De la crítica. Compendio de sociología de la emancipación. (Trads. T. Fernández y B. Eguibar) Madrid, España: Akal.

Boltanski, L., y Thévenot, L. (1991). De la justification. Les économies de la grandeur. París, France: Gallimard.

Contreras, B. (2012). La sabiduría práctica en la ética de Paul Ricour. Santiago de Chile, Chile: Pontificia Universidad Católica de Chile - Plaza y Valdés.

Honneth, A. (1997). La lucha por el reconocimiento. Por una gramática moral de los conflictos sociales, (Trad. M. Ballestero). Barcelona, España: Crítica.

Honneth, A. (2012). The I in We. Studies in the Theory of Recognition (Trad. J. Ganahl).
Cambridge, United Kingdom: Polity Press.

Jervolino, D. (2008). Per una filosofia della traduzione. Brescia, Italia: Morcelliana.

Kearney, R. (2010). Le paradigme de la traduction. En G. Vincent, y J. Porée (Eds.), Paul Ricour. La pensée en dialogue (pp. 169-181). Rennes, France: Presses Universitaires de Rennes.

Ladmiral, J. R. (1994). Traduire: théorèmes pour la traduction. París, France: Gallimard.

Nagel, T. (2006). Igualdad y parcialidad. Bases éticas de la teoría política. (Trad. J. Álvarez) Barcelona, España: Paidós.

Prada, M. (2014). Reconocimiento mutuo. La desmesura de una utopía. En T. Domingo y A. Domingo (Eds.), Congreso Internacional de Bioética y Hermenéutica. La ética deliberativa de Paul Ricoeur. Valencia: Hermes - Universitat de Valencia.

Prada, M. (2015). La idea de reconocimiento en el Hegel de Jena. Una lectura con Paul Ricœur. Franciscanum, LVII(163), 21-49.

Prada, M. (2017). Entre disimetría y reciprocidad. El reconocimiento mutuo según Paul Ricoeur. Bogotá, Colombia: Aula de $\mathrm{Hu}-$ manidades - Editorial Bonaventuriana.

Ricœur, P. (1990). Soi-même comme un autre. París, France: Seuil.

Ricœur, P. (1995). Le juste. París, France: Esprit.

Ricour, P. (2000). La mémoire, l'histoire, l'oubli. París, France: Seuil.

Ricœur, P. (2001). Le juste 2. París, France: Esprit.

Ricœur, P. (2004a). Parcours de la reconnaissance. Trois études. París, France: Stock.

Ricœur, P. (2004b). Sur la traduction. París, France: Bayard. 
Steiner, G. (2001). Después de Babel. Aspectos del lenguaje y la traducción (3. ${ }^{\mathrm{a}}$ Ed.). (Trads. A. Castañón y A. Major). México: Fondo de Cultura Económica.

Taylor, C. (2009). La política del reconocimiento. En C. Taylor y A. Gutmann (Eds.), El multiculturalismo y la "política del reconocimiento" (2. ${ }^{\mathrm{a}}$ Ed.) (Trans. M. Utrilla, L. Andrade, y G. Vilar) (pp. 53-116). México: Fondo de Cultura Económica.

Todorov, T. (2005). Nosotros y los otros. Reflexión sobre la diversidad humana (4.. $\mathrm{Ed}$.). (Trad. M. Mur). México: Siglo XXI.

Woodsworth, J. (Ed.) (2018). The Fictions of Translation. Amsterdam - Philadelphia: John Benjamins Publishing.

\section{Notas}

${ }^{1}$ Incluso se llega a hablar de un "giro filosófico de la traducción» para referirse a la centralidad de este asunto en la reflexión contemporánea (Ladmiral, 1994, pp. V-XXI, en Jervolino, 2008, p. 8), o como una «metáfora maestra» para pensar problemas tanto lingüísticos, como literarios, éticos e incluso políticos (Woodsworth, 2018).

${ }^{2}$ Es necesario aclarar que en el presente trabajo no se pretende hacer un balance, ni plantear una discusión general sobre el amplísimo campo de estudios sobre la traducción. Para un panorama general de este campo, ver: Bielsa, 2016; Bolaños, 2016; Lillebø, 2014; Maitland, 2017; Malmkjaer, 2018.

${ }^{3}$ Para los lectores no familiarizados con esta obra de Ricœur, conviene mencionar que el tercer estudio está dedicado al reconocimiento mutuo. De la mano de Hegel y Honneth, especialmente, Ricœur expone tres formas de reconocimiento mutuo: las relaciones amorosas (familiares, de pareja, amicales); el ámbito jurídico (en el que prima la idea del sujeto de derecho) y la estima social. En cada tramo, Ricœur dialoga con diversos autores que le permiten configurar su propia argumentación. Cuando arriba a la estima social, De la justification -junto con Les puissances de l'expérience de J. M Ferry y The politics of recognition de C. Taylor- es una de las obras en las que más se inspira el filósofo francés (sugerimos ver: Prada, 2017, pp. 147-170).

${ }^{4}$ Ricœur (2004a) resalta que la reflexión contemporánea sobre el reconocimiento se ha centrado casi exclusivamente en el problema de la identidad, especialmente gracias al célebre trabajo de Charles Taylor (2009, pp. 53-116, original publicado en 1994).

5 Este trabajo de la sociología francesa ya había sido comentado por Ricœur en: 1995, pp. 121-142.

${ }^{6}$ Ricœur relaciona esta idea con aquella de T. Nagel (2006, p. 25) según la cual toda vida importa tanto como la mía.

${ }^{7}$ Ver la crítica que hace Steiner en Después de Babel a la idea de una matriz universal de la lengua preconizada, según él, por Chomsky y los defensores de una gramática generativa.

${ }^{8}$ Esta opción de Ricœur tiene que ser leída, no como una rendición a un contextualismo soso que reivindica la diferencia por la diferencia, sino en clave de sabiduría práctica que, si bien privilegia a la persona, "consiste en inventar los comportamientos que mejor satisfagan la excepción exigida por la solicitud, traicionando lo menos posible a la regla" (Ricœur, 1990, p. 312; sugerimos ver: Contreras, 2012). 